\title{
Fragmentos de um periódico perdido \\ a Sentinela do Serro e o sentido da "republicanização" (1830-1832)*
}

\section{Pieces of a disappeared newspaper \\ the Sentinela do Serro and the meanings of "republicanization" (1830-1832)}

\author{
VALDEI LOPES DE ARAUJO \\ Professor de Teoria e História da Historiografia na UFOP \\ Pesquisador do NEHM/UFOP e CEO/Pronex \\ Rua Diogo de Vasconcelos, 122 - CEP 36.400-000 - Ouro Preto/MG \\ valdeiaraujo@ichs.ufop.br \\ WEDER FERREIRA DA SILVA \\ Doutorando do Programa de Pós-Graduação em História Social da UFRJ. \\ Bolsista do ICAM - Instituto Cultural Amílcar Martins. \\ wedhistoria@yahoo.com.br
}

RESUMO A partir da atuação do jovem Teófilo Ottoni, no contexto das disputas que levaram à abdicação do imperador Pedro I, tentamos caracterizar certos traços da linguagem e cultura políticas vigentes no período. A Sentinela do Serro, periódico editado por Ottoni entre 1830 e 1832, e hoje desaparecido, teve destacada atuação na luta pela republicanização da vida política. Neste artigo analisamos fragmentos da Sentinela transcritos em outros jornais do período e os confrontamos com as interpretações consolidadas por Ottoni em sua autobiografia política publicada em 1860. Por fim, argumentamos pela necessidade de matizar a classificação política

* Artigo recebido em: 2/06/2011. Autor convidado. 
ternária (exaltados, moderados, conservadores) geralmente utilizada para caracterizar esse momento, apontando para as limitações dessa abordagem normativa para a compreensão da especificidade da experiência republicana vivenciada por Ottoni e seus correligionários.

Palavras-chave Regência, periodismo, republicanismo

ABSTRACT Studying the young politician Teofilo Ottoni, this paper characterizes some aspects of Brazilian political culture and languages in the 1830's. The Sentinela do Serro, a newspaper edited by Ottoni between 1830 and 1832, and nowadays disappeared, played an important role in the disputes to republicanize Brazilian political life. Here we analysis some Sentinela's fragments published in different contemporary newspapers in order to confront them with interpretations made by Ottoni when he published his autobiography in 1860. Finally, we argue to the necessity of revise the triadic political definition (radicals, moderates, conservatives) generally applied to categorize this moment. This normative approach limits the understanding of some fundamental aspects of the republican experience made by Ottoni and his supporters.

Keywords Brazilian Regency, newspaper, republicanism

\section{Introdução}

Conforme apontou IImar Rohloff de Mattos, os construtores da nação brasileira pós-abdicação participaram de um período marcado por anos de intensa atividade política que mobilizou boa parte da elite imperial. Ao colocar em prática os mais diversos projetos de modernização para o Brasil oitocentista, aqueles que participaram ativamente desse processo expunham e colocaram em prática suas ideias e programas. ${ }^{1}$ Ao tratar do processo de "formação" da elite política imperial, José Murilo de Carvalho acrescenta que os acontecimentos políticos que sucederam o Sete de Abril proporcionaram uma nova fase na trajetória da vida nacional: "assistem-se a choques de todo tipo. Através deles, arma-se a estrutura da nação. Da luta entre grupos ou facções surgem os partidos; das explosões populares, que chegam a assustar o separatismo de algumas partes sairá a verdadeira unidade, livre de perigos ou riscos. ${ }^{2}$

1 MATTOS, IImar Rohloff de. O tempo Saquarema. São Paulo: Hucitec; Brasília: INL, 1987, p.1 (Coleção Estudos Históricos)

2 CARVALHO, José Murilo. Teatro de sombras: a política imperial. São Paulo: Vértice: Editora Revista dos Tribunais; Rio de Janeiro: IUPERJ, 1988, p.11. 
Por ter atuado decisivamente em algumas das querelas políticas de grande relevo para a História do Brasil imperial, o estudo da trajetória de Teófilo Benedito Ottoni (1808-1869) pode nos auxiliar na compreensão das ideias e das ações dos "construtores e herdeiros" do Estado nacional brasileiro no Oitocentos. Para tanto, nossa proposta consiste não apenas em investigar a atuação política de Ottoni, também se tentará discorrer sobre as dimensões que compreendem os discursos políticos produzidos pelo liberal mineiro. Em sua atuação na esfera pública no Brasil oitocentista, o referido político versa sobre questões que estavam na ordem do dia para a elite imperial que "guiou" as ações para estruturar o Estado nacional brasileiro. Neste artigo nos concentraremos anos em torno do Sete de Abril de 1831, experiência decisiva na formação da identidade política de Ottoni e sua geração.

Do ponto de vista metodológico, queremos perguntar sobre o que Ottoni estava fazendo ao publicar seus textos, e de que forma eles podem ser mais bem compreendidos se lidos no interior dos debates políticos e das linguagens vigentes à época de sua primeira articulação. Portanto, estamos à procura menos de definições normativas ou definições teóricas e mais de uma descrição da dimensão histórico-pragmática desse discurso. Para além das querelas e do esforço de taxonomia política, pretendemos apenas restituir o sentido de parte do vocabulário e das linguagens políticas disponíveis na rica conjuntura dos anos de 1830 no Brasil.

Para Poccock, os participantes do debate político - vistos como atores históricos, reagindo uns aos outros em uma diversidade de contextos lingüísticos - proporcionam a textura para a investigação histórica da política. ${ }^{3}$ Assim, através dos pares conceituais subjacentes aos conceitos de langue e parole, procuraremos compreender nas fontes em questão as estratégias presentes nos atos de fala e nas performances discursivas criadas por Teófilo Ottoni.

O presente artigo está dividido em três seções. Na primeira apresentamos um rápido panorama da trajetória política de Teófilo Ottoni, seguindo, de maneira geral, os contornos que ele mesmo traçou na Circular aos eleitores Mineiros (doravante Circular). Na segunda parte analisamos os usos e significados que atribui a sua atuação como redator do desaparecido Sentinela do Serro, de modo a poder, na terceira e última seção, confrontar a imagem projetada com os vestígios do jornal rastreados na imprensa, em especial a moderada, entre os anos de 1830 e 1832. Ao fim, pretendemos contribuir para enriquecer nosso conhecimento da cultura política desses anos, em especial com relação à emergência de um discurso republicano.

3 POCCOCK, John. O estado da arte. In: Linguagens do ideário político. São Paulo: Edusp, 2003, p.25. 


\section{Um personagem entre a história e o mito}

Teófilo Benedito Ottoni nasceu em 27 de novembro de 1807 na Vila do Príncipe, comarca do Serro Frio, Minas Gerais e faleceu no Rio de Janeiro em 17 de outubro de 1869. Foi o primogênito entre os doze filhos do político Jorge Benedito Ottoni e de D. Rosália de Souza Maia. Casou-se em 10 de novembro de 1841 no Rio de Janeiro com D. Carlota Amália de Azevedo Cunha, filha do Conselheiro Joaquim Francisco de Azevedo e de D. Marianna de Azevedo Cunha.

Da pequena Vila do Príncipe até sua eleição ao senado do Império em 1863 a trajetória de Teófilo Ottoni, assim como a de sua geração, ${ }^{4}$ foi marcada pela atuação decisiva e polêmica em diversos episódios de relevo da história do Brasil Império. Assim como o fez em todos os empreendimentos de sua carreira, Teófilo Ottoni procurou deixar registros minuciosos de como entendia sua própria atuação. Exímio produtor de imagens fortes e eficazes, seja o Pojirum dos "selvagens do Mucuri" ou o famoso lenço branco à frente da multidão na Questão Christie, ${ }^{5}$ Ottoni continua a inquietar a imaginação de historiadores, políticos e biógrafos, recebendo deles novas figurações: o bandeirante moderno, de Godofredo Ferreira; ${ }^{6}$ o pioneiro do nordeste mineiro, do Frei Olavo Timmers; ${ }^{7}$ o ministro do povo, de Paulo Pinheiro Chagas; ${ }^{8}$ o campeão da liberdade de Daniel de Carvalho; ${ }^{9}$ o mais adiantado político liberal do Império de Basílio de Magalhães ${ }^{10} \mathrm{e}$, recentemente, o mais "conspícuo representante do que se poderia chamar de liberalismo republicano mineiro". ${ }^{11}$

Entre os documentos de maior repercussão de sua trajetória, a famosa Circular é uma espécie de autobiografia publicada em 19 de setembro de

4 Para Jean François Sirinelli o conceito de geração, malgrado suas "restrições" e "obstáculos", configuram-se em elemento incontestável para a análise histórica. Neste sentido, ele contribui para reabilitar o acontecimento, na medida em que a investigação de um acontecimento inaugurador pode revelar traços que marcam indelevelmente a trajetória atores sociais, possibilitando, assim, uma maior nitidez daquilo que o autor caracteriza como "respirações do tempo". Neste caso, especificamente, o acontecimento inaugurador é a Abdicação de D. Pedro I, acontecimento fundamental para o entendimento do percurso da história do Brasil oitocentista e da atuação daqueles que atuaram na construção e consolidação do Estado imperial. Cf: SERINELLI, Jean François. Geração. In: FERREIRA, Marieta de Moraes e AMADO, Janaína. (orgs.) Usos e abusos da História oral. $8^{a}$ ed. Rio de Janeiro: Editora da FGV, 2006, p.135-137.

5 DUARTE, Regina Horta. Tempo, política e transformação: Teófilo Otoni e seu lenço branco. Estudos Ibero-Americanos, Porto Alegre, n.1, v.XXVIII, p.101-110, 2002

6 FERREIRA, Godofredo. Os bandeirantes modernos: o desbravamento e a colonização das matas do valle do Mucury e a fundação da cidade de Theofilo Ottoni em Minas Gerais. Belo Horizonte: s/ed., 1934.

7 TIMMERS, Frei Olavo (O.F.M). Theophilo Benedicto Ottoni, pioneiro do nordeste mineiro e fundador da cidade de Teófilo Ottoni. 1969.

8 CHAGAS, Paulo Pinheiro. Teófilo Ottoni: ministro do povo. Belo Horizonte: Itatiaia; Brasília: Instituto Nacional do Livro, 1978.

9 CARVALHO, Daniel de. Traços de uma grade vida. Teófilo Ottoni, campeão da liberdade. Rio de Janeiro: Alba, 1934.

10 MAGALHÃES, Basílio de. A circular de Teófilo Ottoni. Revista do Instituto Histórico e Geográfico Brasileiro, t.LXXVIII, parte 2, p.145, 1915.

11 ARAUJO, Valdei Lopes de. A instrumentalização da linguagem. Revista do Arquivo Público Mineiro, Belo Horizonte, Ano XLIV, n.2, p.50-61, julho-dezembro de 2008. Ver também: ARAUJO, Valdei Lopes de. Teófilo Benedito Ottoni: a força histórica de uma experiência moderna. In: Teófilo Benedito Ottoni e a Companhia do Mucuri: a modernidade possível. Belo Horizonte: Secretaria de Estado da Cultura/Arquivo Público Mineiro, 2007, p.15. 
1860 no Rio de Janeiro, sendo esta, nas palavras de Francisco Iglésias, "muitas vezes inteligente, mas quase sempre sectária". ${ }^{12}$ A publicação da Circular reacendeu os ânimos dos partidos Liberal (luzias) e Conservador (saquaremas), até então arrefecidas devido a Política de Conciliação, implementada por Honório Hermeto Carneiro de Leão, o marquês de Paraná.

No referido documento, Ottoni procura convencer os leitores de sua linearidade de pensamento, cujas raízes se encontram nos tempos da juventude, ou como prefere o político, no "verdor dos anos". Interessante notar que Ottoni atrela a história do Império à sua própria trajetória de vida. Assim, quando as movimentações pela independência ecoaram pelo Brasil, como num golpe de sorte também aflorou no peito do jovem Ottoni o sentimento de liberdade que iria guiá-lo em todas as suas ações políticas século XIX adentro. Daí a dimensão mítica que conecta o nascimento nacional e pessoal em um só movimento:

Eu contava com apenas 13 anos de idade quando em 1821 ecoou pelo Brasil o grito pela liberdade.

Levantado no Porto em 24 de agosto de 1820, repercutiu sucessivamente no Pará, na Bahia, e chegou ao Rio de Janeiro a 26 de fevereiro de 1821.

Foi uma faísca elétrica que, passando pelo espírito patriótico de meu pai, o Sr. Jorge Benedito Ottoni, abrasou-me também a jovem imaginação (...) e enraizavam em meu espírito as ideias liberais. ${ }^{13}$

Após concluir o ensino elementar no Serro, Ottoni desembarca no Rio de Janeiro em 1826 para se matricular no curso de engenharia mecânica da Academia da Marinha, local em que entrou em contato com Joaquim José Rodrigues Torres, depois visconde de Itaboraí. Em suas aulas, o então liberal e futuro membro da chamada Trindade Saquarema, ensinava mecânica e também lições sobre as ideias liberais de Thomas Jefferson, "de quem era caloroso encomiasta e eloqüente expositor". ${ }^{14}$

Foi nesta ambiência intelectual que o serrano ingressou no Clube dos Amigos Unidos, ${ }^{15}$ liderado pelas relevantes figuras de Evaristo da Veiga, Bernardo Pereira de Vasconcelos e Cipriano Barata. Em 1829, sob o pseudônimo de Jovem pernambucano, começa a fazer oposição ao governo de Pedro I em jornais da corte, como o O independente (de Joaquim José Rodrigues Torres) e Astréia (de Antônio José do Amaral e de José Joaquim

12 IGLÉSIAS, Francisco. Vida política, 1848/1868. In: HOLANDA, Sérgio Buarque de. (dir.) História geral da civilização brasileira. (O Brasil monárquico: reações e transações) São Paulo; Rio de Janeiro: Difel, 1976, v.3, t.ll, p.80.

13 OTTONI, Teófilo Benedito. Circular dedicada aos srs. eleitores de senadores pela província de Minas Gerais no quadriênio atual no quadriênio atual e especialmente dirigida aos srs. eleitores de deputados pelo segundo distrito eleitoral da mesma província para a próxima legislatura pelo ex-deputado Teófilo Benedito Ottoni. Revista do Instituto Histórico e Geográfico Brasileiro, Rio de Janeiro, t.LXXVIII, parte 2, 1915, p.200.

14 OTTONI, Teófilo Benedito. Circular..., p.203.

15 De acordo com o autor da Circular, o Clube dos Amigos Unidos originalmente proveio da loja maçônica Grande Oriente do Passeio Público. Ao ingressar na entidade, Teófilo Ottoni logo se tornou secretário da mesma instituição. Cf: OTTONI, Teófilo Benedito. Circular..., p.202. 
de Vieira Souto). Em sua província natal Ottoni colaborou com o Astro de Minas, de São João del Rei e Eco do Serro, da Vila Diamantina.

Sobre a Academia da Marinha, Ottoni a acusa de ser uma instituição arcaica e elitista. Por discordar publicamente das regras da instituição, Ottoni queixa-se em sua Circular que sofreu represálias de oficiais de alta patente da Academia. De acordo com o político liberal, seus superiores na Marinha sugeriram que o mesmo fosse participar de missões na costa da África e no Baixo Amazonas. Diante da situação delicada, Teófilo Ottoni retorna ao Serro Frio, levando consigo uma pequena tipografia, responsável pela impressão da Sentinela do Serro.

Para José Murilo de Carvalho, Teófilo Ottoni possuiu um percurso político de lógica impecável. ${ }^{16}$ Ferrenho opositor do chamado "governo pessoal" de Pedro I, Ottoni constituiu-se em figura de grande importância não só para o Sete de Abril como também em outros episódios de destaque na trajetória política do Brasil. Em períodos de crise institucional em Minas Gerais, teve participação importante na chamada Sedição do Ano da Fumaça (1833), recrutando combatentes no Serro para auxiliar no possível ataque ao "governo intruso" que se instalou em Ouro Preto. ${ }^{17}$ Atuou firmemente e foi um dos principais entusiastas do processo que antecipou a aclamação de Pedro de Alcântara em 1840. Em 1842, o político liderava em Minas Gerais a malograda Revolução Liberal, momento que ficou preso, recebendo a alcunha pejorativa de Luzia - vocabulário político que viria rotular todos aqueles que se alinharam ao Partido Liberal. Cerca de dois anos mais tarde o "rebelde" foi anistiado pelo júri da Câmara de Mariana.

Após o insucesso da Revolução Liberal, Ottoni abandonará temporariamente a vida política em 1847 para dedicar-se ao projeto da Companhia de Navegação e Comércio do Mucuri, responsável por construir a primeira estrada em moldes modernos no Brasil. Nesta empreitada também fundou a povoação de Filadélfia (clara alusão à homônima norte-americana), primeira cidade-empreendimento da história urbana de Minas Gerais, atraindo para os sertões do vale do Mucuri imigrantes estrangeiros de diversas nacionalidades. ${ }^{18}$ Ainda de acordo com José Murilo de Carvalho, "mais do que os Inconfidentes, Teófilo Ottoni exibiu traços do moderno e do republicano na vertente norte-americana: liberdade, espírito empresarial, participação política, desejo de mudança, tudo simbolizado no gesto fundador da Nova Filadélfia". ${ }^{19}$

16 CARVALHO, José Murilo de. Trajetórias republicanas. Revista do Arquivo Público Mineiro, Belo Horizonte, ano XLIV, n.2, p.28, julho a dezembro de 2008.

17 Para uma análise da Sedição do Ano da Fumaça, Cf: GONÇALVES, Andréa Lisly. Estratificação social e mobilizações políticas no processo de formação do Estado Nacional brasileiro: Minas Gerais, 1831-1835. São Paulo/Belo Horizonte: Hucitec/Fapemig, 2008, p.78-87.

18 FERREIRA, Weder. Colonização, política e negócios: Teófilo Benedito Ottoni e a trajetória da Companhia do Mucuri (1847-1863). Ouro Preto: Universidade Federal de Ouro Preto, 2009 (História, Dissertação de Mestrado).

19 CARVALHO, José Murilo de. Trajetórias republicanas, p.28 
Em 1860, ao publicar a Circular, Teófilo Ottoni retorna à vida pública elegendo-se deputado pelo Rio de Janeiro e por sua província natal. Regressa à Câmara dos deputados como líder do Partido Liberal, reacendendo antigas rivalidades entre luzias e saquaremas com discursos inflamados nas tribunas, em panfletos, opúsculos e em artigos que reverberavam nas páginas de diversos periódicos da Corte e das províncias. Preterido cinco vezes pelo imperador para o assento no senado, somente em 1863 assumiu uma cadeira na câmara vitalícia do Império. Seu último ato público de relevância para a história do Império foi ter apoiado e assinado o Manifesto do Centro Liberal, publicado em março de 1869 - precursor do Manifesto Republicano, publicado em 3 de dezembro de 1870. No dia cinco de outubro de 1869 Teófilo Ottoni comparece no senado pela última vez. Doze dias depois falecia o político liberal mineiro. Para seus biógrafos e também para a historiografia, Teófilo Ottoni constituiu-se em um dos mais enigmáticos políticos do período imperial, um homem que foi capaz de se reinventar politicamente e ainda assim produzir uma coerência discursiva impressionante. Mito político vivo, Ottoni foi abundantemente representado por inimigos e admiradores. O que foi em vida continuou a ser na história; admirado e denegrido, exaltado ou subestimado; difícil tem sido ignorar o legado deixado por Ottoni seja como político, empresário ou historiador de si mesmo. A seguir, tentaremos confrontar as sempre citadas páginas da Circular nas quais Ottoni interpreta sua atuação no Sete de Abril como redator da Sentinela do Serro.

\section{A Sentinela na Circular aos Eleitores Mineiros}

De acordo com José Murilo de Carvalho todos os exemplares da Sentinela do Serro desapareceram misteriosamente de bibliotecas e arquivos..$^{20}$ Cabe lembrar que o próprio Sacramento Blake já dava conta do desaparecimento da Sentinela ainda no século XIX. Vasto conhecedor das publicações periódicas do Brasil oitocentista, o autor do Dicionário Bibliográfico Brasileiro afirma nunca ter visto a Sentinela, tampouco poderia precisar quando teria cessado sua circulação. ${ }^{21}$

Malgrado o desaparecimento do periódico, é possível reabilitar alguns fragmentos dos artigos. José Murilo de Carvalho o fez ao recuperar o artigo de José Teixeira das Neves, publicado nos Anais da Biblioteca Nacional. No fragmento recuperado é possível reconstituir as acepções que moldaram o discurso político de Teófilo Ottoni. Neste sentido, o conteúdo

20 CARVALHO, José Murilo de. Trajetórias republicanas, p.35. Ver nota 18.

21 BLAKE, Francisco Vitorino de Sacramento. Theophilo Benedicto Ottoni. In: Dicionário Bibliográfico Brasileiro. Rio de Janeiro: Tipografia Nacional, 1883, p.267. Pela Circular sabemos que o jornal deixou de Circular em 1832, mas por ela não é possível precisar exatamente quando. 
do texto é paradigmático para compreender a influência da cultura política estadunidense em Ottoni. Nas páginas da Sentinela o político mineiro dizia de forma laudatória que seu partido era o daqueles que desejavam que o Brasil imitasse a terra de George Washington e que o nosso povo deveria ser em tudo semelhante ao povo norte-americano. E dizia ainda: "O nosso Norte é a Liberdade Americana, a liberdade da Pátria de Franklin, única que nos agrada; e pela qual sacrificaremos a própria vida, se preciso for". ${ }^{22} \mathrm{Na}$ avaliação de José Murilo de Carvalho, seria difícil encontrar mais enfática manifestação de adesão aos valores da liberdade em sua matriz norte-americana. ${ }^{23}$

No que se refere aos periódicos de oposição a Pedro I, Lúcia Bastos Pereira das Neves destaca que estes forneciam mais opinião do que notícias, a partir de reuniões secretas em clubes, deslocaram o espaço da discussão política para fora da Câmara dos deputados e da esfera pública de poder. Tiveram atuação decisiva no Sete de Abril de 1831 periódicos de conotação moderada como a Astréia, a Aurora fluminense e A malagueta e jornais exaltados, como foi o caso do Nova luz brasileira, O tribuno do povo e o O repúblico, editados na Corte; o Observador constitucional, em São Paulo a Gazeta paraibana, a Abelha pernambucana e o já citado Sentinela do Serro. ${ }^{24}$

Ottoni não só procurou evidenciar explícita oposição ao autoritarismo de D. Pedro I como também convocou a população do Serro a sair às ruas para "deitar armas" em apoio aos fluminenses nos conflitos das noites das Garrafadas, contra a tirania daquilo que denominava de "governo pessoal". Segundo José Murilo de Carvalho esta atitude de Ottoni lembrava a figura de um town meeting da Nova Inglaterra. ${ }^{25}$ Nesta atuação o político mineiro conseguiu reunir na praça central do Serro todas as autoridades da cidade para arrecadação de fundos para a compra de armas, pólvora e salitre, afim de compor um arsenal para um possível confronto - na oportunidade, foram arrecadados a significativa quantia de 11 contos de réis (11:000\$000).

De acordo com Ottoni, somente na noite do dia 22 de abril de 1831 a notícia sobre a Abdicação chegava ao Serro. Seu pai, Jorge Benedito Ottoni, à época deputado no Conselho Provincial em Ouro Preto, enviara uma carta em que se comentava os acontecimentos da Corte. Eis a descrição de como foi acolhida no Serro a notícia da abdicação do trono:

\footnotetext{
22 Apud: NEVES, José Teixeira das. Periódicos mineiros na Biblioteca Nacional. Anais da Biblioteca Nacional, Rio de Janeiro, v.117, p.305, 1997. Ver CARVALHO, José Murilo de. Trajetórias republicanas, p.26.

23 CARVALHO, José Murilo de. Trajetórias Republicanas, p.26.

24 NEVES, Lúcia Bastos Pereira das. Abdicação. In: VAINFAS, Ronaldo. (dir.) Dicionário do Brasil Imperial (1822-1889). Rio de Janeiro: Objetiva, 2002, p.12-13

25 CARVALHO, José Murilo de. Trajetórias republicanas, p.26.
} 
Instantaneamente a cidade iluminou-se, bandas de música acompanhavam a guarda cívica e a população em massa, que até ao romper do dia percorreram as ruas, cantando hinos patrióticos, entre vivas à liberdade, à Revolução de Sete de Abril, ao redator da Sentinela do Serro, etc, etc. ${ }^{26}$

As páginas da Sentinela também foram utilizadas por Ottoni para descrever suas concepções acerca do liberalismo e do modelo pelo qual se deveriam guiar a evolução política do Império após o Sete de Abril. Face à riqueza de detalhes, cabe aqui reproduzir o trecho transcrito para Circular forma mais detalhada:

Somos de opinião que se deve lentamente republicanizar a constituição do Brasil cerceando as fatais atribuições do poder moderador, organizando em assembléias provinciais os conselhos gerais de província, abolindo a vitalicidade do senado, e isso desde já. Mas se, contra nossa humilde opinião, a câmara dos deputados se conservar estacionária, nem por isso apelaremos para golpes da nação; mas, pelo contrário, continuaremos a reprovar altamente todos os meios violentos, que podem levar-nos à anarquia e depois ao despotismo militar, que oprime a quase todas as chamadas repúblicas da América ex-espanhola. Ainda assim, pois, recomendaremos obediência aos decretos legais da assembléia geral. Esperaremos pela próxima legislatura, e, fazendo ver aos nossos patrícios a necessidade de atenuar legalmente o demasiado vigor que a constituição dá ao sempre funesto elemento monárquico, apontaremos pelo nome os deputados amigos das reformas constitucionais, para serem reeleitos, e os deputados estacionários ou retrógrados, não para os insultar, mas para que o povo os exclua da representação nacional. ${ }^{27}$

Para os objetivos deste trabalho, cabe pensar o que significava o vocabulário "republicano" para Teófilo Ottoni. Podemos inferir que a ideia de república define um projeto político conduzirá a trajetória do liberal mineiro. Para Ottoni, a ideia de república deveria ser um ideal a ser seguido, de modo que esta etapa política deveria ser uma evolução natural do sistema monárquico. ${ }^{28}$ Neste sentido, Ottoni - assim como muitos outros políticos de sua geração - articulava uma linguagem política que em muitos aspectos estava atrelada a um modelo clássico (ou aristotélico) de sucessão histórica das formas de governo. Daí o temor de que os excessos democráticos pudessem arrastar o Império do Brasil às "funestas falanges da anarquia" e do despotismo - como julgava ser o caso das repúblicas americanas que emergiram da fragmentação do antigo Império Espanhol.

O político destaca que na agitação e devaneio de sua luta contra o governo pessoal de Pedro I vislumbrava uma forma que se fundamentava numa democracia pacífica, isto é, um modelo democrático que deveria ser

26 OTTONI, Teófilo Benedito. Circular..., p.208

27 OTTONI, Teófilo Benedito. Circular..., p.213. (grifo do autor)

28 ARAUJO, Valdei Lopes de. A instrumentalização da linguagem, p.54. 
guiado por certa classe média, enfim, uma "democracia da gravata lavada, que com o mesmo asco repele o despotismo das turbas ou a tirania de um só". ${ }^{29}$

Assim como o modelo gradualista de governo estava atrelado a elementos aristotélicos, podemos observar no fragmento acima transcrito que para Teófilo Ottoni a ideia de democracia também derivava de elementos clássicos. Como já foi percebido por Antônio Cândido, o conceito de democracia operado por Ottoni apresentava-se de forma restritiva, ou seja, não poderia ser estendido à totalidade da população, dentre outros fatores pelo fato de o exercício da vida republicana exigir certas virtudes do cidadão. ${ }^{30}$ Esta perspectiva fica explícita no artigo compilado da edição $n^{\circ}$. 43 da Sentinela do Serro de 21 de junho de 1831, reproduzida na Circular:

Trezentos anos de escravidão não podem bem preparar um povo para entrar no gozo da mais perfeita liberdade. Um povo educado sob o despotismo, sem ideia alguma sobre a organização do corpo social, de mais imbuído pelos seus tiranos em princípios errôneos, fautores [sic] do despotismo, precisam de ótimos guias para se não desviar e perder nas ignoradas veredas que devem conduzi-lo ao templo da divina liberdade. Maus guias podem levá-los aos horrores da anarquia, ou entregá-lo dinovo às garras do poder absoluto. Estes os dois medonhos cachopos que ameaçaram a nau do Estado desde os primeiros ensaios que fizemos para a nossa regeneração política.

Como era argumento comum, os excessos da liberdade poderiam levar a "nau do Estado" ao despotismo ou à anarquia, daí o fato de Ottoni alinharse à causa monárquica em detrimento dos movimentos que, ao fim e ao cabo, acarretariam na fragmentação do Império durante o período regencial. Somente por etapas seria possível colocar em curso o seu projeto político de republicanizar as instituições Imperiais. Releva-se então um processo de transformação que deveria ser paulatino. Por fim, seu republicanismo passa a ser o zelo pelo funcionamento adequado de uma monarquia parlamentar, somente assim seria garantida a ordem e a integridade da jovem nação. ${ }^{31}$ De todo modo, o programa da lenta republicanização não era sinônimo do "popularizar a monarquia" que podemos ler no Aurora, este mais próximo da ideia de que a monarquia constitucional poderia ser a melhor das repúblicas, concepção que certamente Ottoni não compartilharia: ${ }^{32}$

29 OTTONI, Teófilo Benedito. Circular..., p.210

30 CÂNDIDO, Antônio. Radicalismos. Estudos Avançados, São Paulo, n.8, v.4, p.9,1988

31 OTTONI, Teófilo Benedito. Circular..., p.211. O tema da carência de homens virtuosos para promover governos republicanos parece ter se espalhado também nas repúblicas latino-americana. Cf: LOMNÉ, Georges. De la "República" y outras repúblicas: La regeneración de un concepto. In: SEBÁSTIAN, Javier Fernandes. Diccionario político y social del mundo iberoamericano. La era das revoluciones, 1750-1850. Madrid: Centro de Estudios Políticos y Constitucionales/CEPC, 2009, p.1267.

32 Sobre questão semelhante para o contexto português, ver: RAMOS, Rui. República - Portugal. In: SEBÁSTIAN, Javier Fernandes. (dir.) Diccionario político y social del mundo iberoamericano. Conceptos políticos en la era de las revoluciones, 1750-1850. Madrid: Centro de Estudios Políticos y Constitucionales/CEPC, 2009, p.1361-1362. 
O Observador Constitucional em n. 175 propôs-se a apresentar suas opiniões com franqueza, e depois de haver traçado um longo artigo reconhecendo que a República perfeita não convém ainda hoje. Faz o nosso colega suas observações sobre a marcha política do Brasil desde 1820, e descobre a tendência do povo brasileiro para as instituições Americanas. Em alguns pontos pensamos com 0 Observador, e somos do número daqueles que não arrepiam ao ouvir a palavra - República, porque nascido na América (...) A Constituição assim reformada concede amplas atribuições às Províncias federadas, serve de sustentáculo às Liberdades públicas, e previne a inteira dissolução do Estado, ao mesmo tempo em que populariza a Monarquia. (Publicada pelo O Novo Argos). ${ }^{33}$

Dessa forma, o Sete de Abril colocaria em voga um projeto que derivou da cultura política constitucionalista do período. A defesa intransigente da Constituição - entendida como elemento fundamental para garantir a Liberdade e a Independência - assegurava o funcionamento do principal mecanismo jurídico-político limitador do poder do Estado por meio da separação entre poder e direito. Além disso, era necessário afastar a nação da turbulência política que conturbava as repúblicas vizinhas.

Ao consolidar o processo que pôs fim ao primeiro reinado, Ottoni se diz contrariado pela oportunidade perdida reformar profundamente a constituição imperial outorgada em 1824. Ao interpretar a tomada do poder pelos moderados, em detrimento dos liberais avançados, Ottoni destacava que o Sete de Abril fora uma verdadeira journeé des dupes, ${ }^{34}$ devido ao fato de que aqueles que haviam concebido, organizado e realizado o movimento acabaram sendo derrotados durante a Regência. Os moderados, que aderiram ao movimento apenas nas vésperas da Abdicação, acabaram por imprimir sobre ele sua liderança. Em uma sempre citada passagem, afirma Ottoni:

O Sete de Abril foi um verdadeiro journeé des dupes. Projetado por homens de ideias liberais muito avançadas, jurado sobre os sangue dos Canecas e dos Ratecliffs, o movimento tinha por fim o estabelecimento do governo do povo por si mesmo, na significação mais lata do termo. ${ }^{35}$

Assim, a imagem que a Circular nos oferece da atuação de Ottoni como o redator da Sentinela é a de um liberal avançado, crítico da anarquia e da moderação tímida. No seu relato, os moderados figuram como os grandes traidores da causa revolucionária, mesmo aquela que no lugar da violência propunha popularizar a monarquia. No lugar de republicanizar, os moderados teriam se aliado aos antigos absolutistas para juntos restaurarem uma

33 Biblioteca Nacional do Rio de Janeiro. (BNRJ) Sessão de Periódicos. (SP). Aurora fluminense. Rio de Janeiro, Tipografia do Diário, n.551, Quarta-feira, 02 de Novembro de 1831, p.2335. Microfilme: PR-SOR 00036 [1-5]. (negrito nosso)

34 Dia dos tolos ou dos enganados, em francês. A expressão tornou-se célebre para definir a tentativa frustrada de Maria de Médici e seus aliados para destituir o Cardeal Richelieu. Desde a Revolução Francesa entraria para o vocabulário político corrente para designar grandes manobras fracassadas.

35 OTTONI, Teófilo Benedito. Circular..., p.209. 
monarquia forte e contrária às bandeiras do Sete de Abril, particularmente o fim da vitaliciedade do Senado, a restrição do poder moderador e a republicanização da vida política, expurgando-a dos vestígios despóticos como o polêmico beija-mão e a excessiva centralização. O profundo deslocamento processado ao longo dos anos de 1830, no qual a ideia de república foi sendo inviabilizada no discurso político, ${ }^{36}$ foi sempre combatida por Ottoni, de certo por discordar que um governo com tanto espaço para o exercício do poder pessoal não poderia realizar o ideal do equilíbrio entre liberdade e autoridade que ele via magistralmente construído no modelo da federação norte-americana.

O quanto essa visão da Circular corresponde ao efetivo programa da Sentinela talvez nunca saibamos ao certo, pois apesar de ter sido publicado regularmente por cerca de dois anos, os exemplares estão até agora perdidos. Mesmo que ainda tenhamos esperanças de encontrar maiores indícios, dificilmente conseguiremos restituir o conjunto de modo significativo. O que faremos a seguir é tentar recuperar artigos da Sentinela transcritos em alguns jornais do período, a maior parte deles apontados pelo próprio Ottoni na Circular, como o Aurora fluminense, $O$ independente e O repúblico. Além de resgatar certos elementos da cultura política em que o jovem Ottoni estava inserido, tentamos complexificar a versão consagrada e sempre repetida que o próprio redator da Sentinela registrou para a posteridade em sua Circular. ${ }^{37}$ Cabe destacar, no entanto, que as transcrições que arrolaremos são quase todas oriundas de jornais moderados, o que impõe outro tipo de filtro ao material original.

\section{Os sentidos da Sentinela à época da Abdicação, em versão liberal moderada}

Um dos motivos alegados por Ottoni para transcrever longos trechos da Sentinela na Circular seria desfazer mal entendidos produzidos por seus adversários políticos que, segundo ele, citavam passagens do periódico fora de seu contexto original. Ottoni procurava demonstrar que embora estivesse alinhado com grupos mais avançados do liberalismo, seu programa à frente da Sentinela sempre fora de uma moderação que não levasse ao adormecimento do princípio da liberdade e nem fosse conivente com a violência e o jacobinismo. No vocabulário dos anos 30 , um dos grandes impasses da vida política era encontrar os meios adequados para conciliar a necessária atividade, movimento e vigor da liberdade, com a ordem pú-

36 Sobre essa questão ver: STARLING, Heloisa Maria Murgel e LINCH, Christian Edward Cyril. República - Brasil. In: SEBÁSTIAN, Javier Fernandes. (dir.) Diccionario político y social del mundo iberoamericano, p.1289-1290.

37 Esforço semelhante podemos encontrar em ARAÚJO MIRANDA, Leonardo Souza de. A democracia da gravata lavada: Teófilo Ottoni, liberdade e espaço público no periódico Sentinella do Serro. In: Anais do XX Encontro Regional de História: História e Liberdade. Franca: ANPUH-SP/UNESP, 06 a 10 de setembro de 2010. 
blica e a autoridade a fim de evitar a guerra civil e os extremos da anarquia e do despotismo. Portanto, de certo modo, Ottoni desqualificava os que tentavam caracterizá-lo como radical e adepto do uso da força em política. É possível que o desaparecimento da Sentinela esteja ligado a um esforço de apagamento de suas passagens mais exaltadas, algo que só conseguiremos apontar indiretamente com o material que segue. Certamente deve ser possível ainda mapear o eventual radicalismo político do jornal, mas é tarefa que ainda exige pesquisa.

Em uma espécie de resenha do periodismo mineiro em outubro de 1830, o Aurora fluminense, de Evaristo da Veiga, identificava dois grandes grupos de jornais em Minas, um primeiro, representado pelo Telégrafo e o Amigo da verdade, continuariam "a revolver-se no mesmo lodaçal de injúrias, abjetas calúnias e ataques à vida privada dos Cidadãos". ${ }^{38}$ Já no grupo liberal, jornais como a Estrela marianense, o Novo Argos e o Universal eram cada vez mais dignos da "causa" que defendiam, apresentando artigos "bem raciocinados" dedicados à instrução do povo "em seus deveres políticos". Após defender que apenas à civilização, e não à violência, que se deviam as grandes transformações políticas do tempo, termina por definir sua concepção de liberdade: "Deixemos a violência e o panegírico da ignorância para os tiranos, e seus satélites. A liberdade que pretendemos não é a do botecudo (sic) errante nos matos, e lutando com as feras, é a dos povos cultos e que gozam de todas as vantagens de uma sociedade melhorada". Enfim, a palavra, e não a violência; a razão e não a paixão, o comércio e não a errância, a civilização e não a selvageria ou a bárbara tirania seriam as marcas dignas da política do século liberal. ${ }^{39}$

Dentre o grupo mineiro, o Aurora chamava a atenção ainda para o surgimento de dois novos jornais, o Pregoeiro constitucional (do arraial de Pouso Alegre) e a Sentinela do Serro (da Vila do Príncipe), ambos dedicados à "ilustrar o povo, torná-lo melhor". No caminho da moderação com energia, "não tratam de azedar paixões violentas, nem de acender furores, sim de fazer amar as instituições, e de mostrar aos cidadãos que se não pode ser livre sem justiça e moralidade". ${ }^{40}$ Especificamente sobre a Sentinela afirma que:

oferece-se para inserir correspondências, mas que não contenham doutrinas contrárias aos princípios liberais, que não tratem de fatos relativos à sua vida privada, e sendo, além disso, escritos no estilo civil e decente que é próprio da gente liberal. Desde já protestamos altamente (continua a Sentinela) que em nossa folha nunca aparecerão os grosseiros convícios, arreieiradas, e insultos à

38 BNRJ. SPR. Aurora Fluminense. Rio de Janeiro, n.394, Sexta-feira, $1^{\circ}$ de Outubro de 1830, p.1667. Microfilme: PR-SOR 00036 [1-5].

39 Sobre Ottoni e o que chama de pedagogia moderada, ver: SILVA, Wlamir. Esmagando a Hydra da discórdia: o enquadramento do pensamento exaltado pela moderação mineira. História, São Paulo, n.2, v.25, p.214-227, 2006.

40 BNRJ. SPR. Aurora Fluminense, n.394, p.1667. 
vida privada que por desgraça nossa enfeitam as páginas de alguns periódicos. - O Brasil avança, ele não perderá a sua liberdade. ${ }^{41}$

Em 22 de outubro, o Aurora voltaria aos periódicos de Minas e à Sentinela do Serro, procurando caracterizá-la como uma força da moderação política, para os quais ser rico não era ainda um crime..$^{42}$ No campo das referências à Revolução Francesa, o jacobinismo era oposto aos grandes mártires girondinos, figurando Robespierre e Marat como os "imundos" ressuscitados pelos insensatos. Um longo trecho atribuído à Sentinela é transcrito e nele defendia-se enfaticamente os nomes de Feijó, Paula Souza, Alencar e Vergueiro contra os que eram denominados ultra-constitucionais, isto é, falsos liberais que seriam, na verdade, "aduladores assíduos de ministros no tempo do infernal absolutismo". ${ }^{43}$ A associação entre virtude e república era constantemente repetida e estava por trás do também insistente clamor pela educação e civilização do povo:

É preciso gritar, e gritar muito alto, que as ideias de liberdade se associam de tal modo com as de justiça, que não pode existir uma sem outra: que as virtudes públicas são uma conseqüência necessária das virtudes particulares: aquele que não é bom pai, bom marido, bom amigo, o passeador ocioso, e inútil, o maléfico, o caloteiro, o intrigante, o debochado, tragam embora sempre na boca o nome da pátria, e da Constituição, não merecem crédito, nem conceito público, não são liberais, nem absolutistas, são meros cata-ventos, que com ligeireza se voltam para o partido, que lhe parece mais lucrativo. ${ }^{44}$

Na continuação, Ottoni citava Madame de Staël, que teria afirmado ser a intolerância um "crime abominável tanto em política quanto em religião". Reclamava que "as arrieiradas, os convícios de tabernas injustamente apresentadas em algumas folhas contra Cidadãos beneméritos têm arrefecido em seus corações o fogo do patriotismo, e os têm feito deixar o terreno às gralhas imposturas, e roucas matracas, que aturdem o tímpano dos ouvidos fracos, e causa horror aos que têm órgãos bem constituídos". O mesmo teria acontecido na Revolução Francesa quando o Terror jacobino levou à destruição dos moderados girondinos, por isso, "a divina liberdade lamentará em todos os tempos a sorte dos Vergniaud, Guadet, Condorcet e Barbaroux". ${ }^{45}$ Na lógica do artigo da Sentinela, trata-se de evitar que a revolução brasileira degenere para o Terror, o único caminho seria "trabalhar na reforma dos costumes, encaminhar, e instruir a Opinião Pública" ${ }^{46}$

41 BNRJ. SPR. Aurora Fluminense, n.394, p.1667

42 BNRJ. SPR. Aurora Fluminense. Rio de Janeiro, n.407, Sexta-feira, 22 de Outubro de 1830, p.1702-1703. Microfilme: PR-SOR 00036 [1-5]

43 BNRJ. SPR. Aurora Fluminense. Rio de Janeiro, n.407, p.1702-1703

44 BNRJ. SPR. Aurora Fluminense. Rio de Janeiro, n.407, p.1702-1703

45 BNRJ. SPR. Aurora Fluminense. Rio de Janeiro, n.407, p.1702-1703

46 BNRJ. SPR. Aurora Fluminense. Rio de Janeiro, n.407, p.1702-1703. 
Esse mesmo universo de referências que tornava a Revolução Francesa uma espécie de prefiguração do Sete de Abril apareceria de novo em um artigo da Sentinela transcrito no Independente em 24 de março de 1832, ${ }^{47}$ já na fase em que o periódico serrano estava sendo proscrito pelo governo regencial. A essência do argumento é a mesma, opor os moderados girondinos aos oportunistas jacobinos. O efeito é produzido por uma alegada fala de Vergniaud em resposta a Robespierre que o acusava de moderado:

Nós moderados! (...) Não; eu não sou no sentido de pretender extinguir a energia nacional: sei que a liberdade é sempre ativa, como a chama que é inconciliável com a mais completa apatia que convém somente a escravos (...) Sei também que em tempos revolucionários tanta loucura seria pretender acalmar o capricho e efervescência do povo, como ordenar às ondas, que estejam tranqüilas, quando são batidas pelos ventos: mas toca ao legislador prevenir, quanto puder, os desastres da tempestade por meio de judiciosos conselhos, e se a pretexto de revolução, é preciso para ser patriota, Declarar-se patrono do assassínio, e do saque; eu sou moderado! (...) A Convenção é o centro em torno do qual devem reunir todos os cidadãos.

Procura-se consumar a revolução pelo terror; quisera eu consumá-la pelo amor. Enfim, não pense que, semelhantes aos padres, e aos ferozes ministros da inquisição, que não falam do Deus das misericórdias, senão no meio das fogueiras, devêssemos nós falar em liberdade, cercados de punhais e de carrascos. ${ }^{48}$

A passagem citada em 1832 reafirmava o caráter de uma oposição constitucional à Sentinela, perseguida naquela ocasião por sua defesa de um golpe parlamentar que propunha eleições para uma nova câmara dos deputados com poderes constituintes para levar adiante reformas como a extinção da vitaliciedade do Senado, a criação das Assembleias Provinciais e imposição de limites estreitos ao Poder Moderador. Ottoni procurava construir um caminho mediano entre os "anarquistas" e os "defensores da república já" e os moderados em seu namoro com os absolutistas.

Mas voltemos ao Aurora fluminense. Após a transcrição de outubro de 1830, só teremos notícias da Sentinela em 04 de março de 1831, às vésperas da "noite das garrafadas" e da radicalização política que levaria à Abdicação de Pedro I. No novo artigo, a Sentinela era usada pelo Aurora para produzir o tão desejado clima de continuidade entre os acontecimentos europeus e brasileiros. Esse clima formava-se na imprensa liberal, como ilustra esse fragmento do O repúblico:

Chegou para a França a época de sua revolução que deve assegurar triunfos por prontos sucessos (...). Este triunfo é infalível; mas, ou a geração presente será a testemunha ou ela o comprará para a seguinte com parte do seu sangue

47 BNRJ. SPR. O independente. Rio de Janeiro: Tipografia de Thomaz B. Hunt, n.65, Sábado, 24 de março de 1832 Microfilme: PR-SOR 00330.

48 BNRJ. SPR. O independente, n.65. 
(...). A volta da antiga ordem de coisas é impossível [pois] uma vez as ideias de justiça, liberdade e igualdade se derramam na massa ativa do povo, elas aí germinam e se desenvolvem dia a dia mais em mais. ${ }^{49}$

Na primeira metade do artigo transcrito no Aurora, Ottoni descreve a conjuntura no Velho Mundo até 1829, exclamando "Como é risonho o aspecto que hoje apresenta a causa da liberdade em todo o Universo!". 50 Até 1829 a Europa estava dominada pela opressão e letargia, a imprensa agrilhoada em todo lugar; na França, na Espanha, na Holanda e na Prússia a liberdade era acuada. Mesmo a Inglaterra estava sob domínio dos conservadores tories. Na América, "a liberdade só podia alçar a frente majestosa no seu antigo asilo, na Pátria dos Paine, dos Jefferson, e dos Francklin". Todo esse quadro pessimista serve apenas para potencializar o efeito climático de uma mudança brusca e irresistível a favor do progresso da liberdade:

Presentemente tudo está mudado: o conclave dos tiranos acha-se quase dissolvido. Na França já nem existe a luta entre oprimidos, e opressores: apenas disputam entre si homens, que todos querem maior, ou menor porção de liberdade. Bélgica proclamou-se independente: a Holanda já saiu do seu letargo. Na Alemanha já se fazem observações à ordem do déspota. Na Espanha já se combate pela divina liberdade: e a esta hora os Espanhóis estão divididos entre 2 exércitos; um composto da canalha, e dos frades; outro dos patriotas e da Nação, e não é duvidoso a quem pertencerá a vitória. Finalmente, para complementar da derrota dos Apostólicos, caiu na Inglaterra o Ministério de Wellington; já se trata de Reformas Constitucionais no Parlamento Britânico, e o leme do estado é dirigido pelo partido Whig, ou liberal. (Da Sentinela do Serro)

Como poderia o Império do Brasil ficar de fora dessa nova fase da história do mundo? A inevitabilidade e urgência do processo são textualmente produzidas pela repetição ritmada do advérbio de tempo: "na França já nem existe"; "a Holanda já saiu"; "na Alemanha já se fazem"; "na Espanha já se combate" e na Inglaterra "já se trata de reformas". Sabemos hoje que também no Brasil, alguns dias depois, já a revolução seria feita, o clima para isso estava sendo a cada dia produzido e comunicado pela imprensa em artigos como esse da Sentinela. Em sete de março, o Aurora seguia no mesmo caminho, complementando o "golpe de vista sobre os sucessos do ano de 1830" oferecido por Ottoni, pois "convinha insistir sobre objetos quase idênticos, agora que os derradeiros acontecimentos da Europa absorvem a atenção de todos os homens pensadores." ${ }^{51}$ Trata-se, de fato, de fazer acreditar que a tendência a favor da liberdade e da revolução era uma força

49 BNRJ. SPR. O repúblico. Tipografia de R. Ogier, Quarta-feira. 06 Outubro de 1830, p.8. . PR-SOR 00026 [1]

50 BNRJ. SPR. Aurora fluminense. Rio de Janeiro: Tipografia do Diário, n.457, Sexta-feira, 04 de Março de 1831, p.1927. Microfilme: PR-SOR 00036 [1-5].

51 BNRJ. SPR. Aurora fluminense, n.458, Segunda-feira, 07 de março de 1831, p.1931. Microfilme: PR-SOR 00036 [1-5]. 
irresistível, a qual poderia ser atribuída inclusive responsabilidade histórica. Criticando uma proclamação de Pedro I, em Ouro Preto, na qual o Imperador afirmava a existência de "um partido desorganizador, que, aproveitando-se das circunstâncias puramente peculiares da França, pretende iludir-vos com inventivas contra a minha inviolável, e sagrada Pessoa, e contra o governo", 52 o Aurora insistia no caráter global e não peculiar da crise:

nada há na proclamação que s.m.i. assinou no Ouro Preto, que dê ideia de reforma ou melhoramento da parte dos governantes; parece lançar-se a culpa toda da desordem, que dizem ameaçar-nos, aos excessos da imprensa periódica (excesso cuja existência aliás confessamos) e a um partido desorganizador, que se aproveitou das circunstâncias puramente peculiares da França. Que os acontecimentos da França estão muito longe de serem particulares, assaz provam todos os resultados de que na Europa tem sido seguidos, para o destino das outras nações. (Grifos do redator)

Em 11 de abril, pode então o redator do Aurora sentenciar, "A nossa revolução gloriosa em nada teve que invejar os três dias de Paris. Os atos de desinteresse e de generosidade, tão admirados na França, foram reproduzidos aqui e se encontram até entre as pessoas da mais infeliz posição social". ${ }^{53}$ Depois da Abdicação, em 07 de abril, a conjunção das forças políticas e os desafios seriam outros, as referências à Sentinela do Serro continuariam na direção da defesa do caminho moderado, mesmo que agora o periódico serrano talvez parecesse menos moderado do que convinha ao momento. Assim, é somente em 15 de junho que encontramos nova citação ao periódico de Vila do Príncipe: "Transladaremos um artigo da Sentinela do Serro, bem conhecida pelo calor do seu estilo, talvez por sua tendência excessiva para as reformas violentas, e que ninguém portanto acusará de moderada ou jesuítica". ${ }^{54}$

Neste artigo, a Sentinela afirmava que não poderia haver liberdade sem respeito ao direito de propriedade e segurança individual; "ordem, respeito às leis, e às autoridades constitucionais". Prossegue criticando duramente as desordens que incentivavam a violência contra os "servis", partidários do absolutismo; "pois quando a força está da nossa parte, é uma vileza, é uma indignidade abusar da fraqueza dos vencidos para espancá-los". O exemplo da Revolução Francesa era novamente evocado para prevenir os "verdadeiros liberais" contra os agitadores que procuravam tirar proveito depois de feita a revolução:

52 BNRJ. SPR. Aurora fluminense, n.460, Sexta-feira, 11 de março de 1831, p.1941. Microfilme: PR-SOR 00036 [1-5]

53 BNRJ. SPR. Aurora fluminense, n.470. Segunda-feira, 11 de Abril de 1831, p. 1984. Microfilme: PR-SOR 00036 [1-5]

54 BNRJ. SPR. Aurora fluminense, n.493, Quarta-feira, 15 de Junho de 1831, p.2096. Microfilme: PR-SOR 00036 [1-5]. (negrito nosso) 
Robespierre escondeu-se, quando os verdadeiros republicanos no dia 10 de Agosto atacaram o palácio de Luis XVI; ganha a batalha, eis o monstro surgindo para vir fazer os massacres de 2 e 3 de Setembro. Temos quase certeza de que isto não sucederá entre nós. Os liberais não o consentirão, ainda que apareçam no Brasil Robespierres. ${ }^{55}$

Os motins que promoviam as cenas de violência não eram, no entanto, simplesmente atribuídos aos jacobinos, mas a uma espécie de infiltração de elementos absolutistas interessados em provocar desordens e produzir "excessos anárquicos", como os patrocinados pelos "agentes da Santa Aliança nas Repúblicas ex-Espanhola". ${ }^{66}$ Até aquele momento, Ottoni diferenciava apenas os "verdadeiros liberais" dos anarquistas e adeptos da tirania; de alguma maneira procurava situar-se em um amplo campo da moderação bem entendida, mas não simplesmente aliado aos que depois conheceríamos como grupo moderado. Na Circular, essa classificação ganharia matizes, definindo Ottoni sua posição na época como "liberal avançada", em oposição aos moderados, anarquistas e conservadores. Os acontecimentos de junho e julho, com a ascensão da Regência Trina Permanente e Feijó na pasta da Justiça, dando início à repressão sistemática aos supostos anarquistas, marcariam o paulatino afastamento de Ottoni daquilo que ia se tornando o grupo moderado.

O seu ex-professor, Rodrigues Torres, ainda mencionaria a Sentinela em seu jornal O independente. Em setembro de 1831, citava o "Patriota Redator da Sentinela do Serro" e transcrevia um longo artigo na mesma linha da defesa da ordem contra os anarquistas. ${ }^{57}$ Antes o redator de $\mathrm{O}$ independente escrevia que suprimira um trecho do artigo por este fazer menção pouco elogiosa a certo indivíduo "entre nós bem conhecido" e que muito mal estava fazendo a seu país. Na Circular Ottoni mantém silêncio sobre o nome dos anarquistas que combatia pela Sentinela, procurando destacar apenas suas diferenças com os moderados. No artigo transcrito, Ottoni faz votos para que o ministério encontre na maioria dos brasileiros o apoio para realizar um governo digno da América. Lembra os levantamentos de parte da polícia do Rio contra o governo, e novamente aponta os "homens sem Pátria, sem moralidade, sem honra, e que em revolução julgam todos os meios lícitos, e bons, contanto, que eles consigam seus fins". ${ }^{58}$ Alerta aos patriotas ardentes que não ouçam o canto dessas "artificiosas sereias, as quais pregam a República ensangüentada, a República já, a República por todos os meios". 59

\footnotetext{
55 BNRJ. SPR. Aurora fluminense, n.493, p.2096.

56 BNRJ. SPR. Aurora fluminense, n.493, p.2096.

57 BNRJ. SPR. O independente. Rio de Janeiro: Tipografia de Thomaz B. Hunt, n.39, Terça-feira, de Setembro de 1831, p.154-155. Microfilme: PR-SOR 00330

58 BNRJ. SPR. O independente, n.39, p.154-155

59 BNRJ. SPR. O independente, n.39, p.154-155. (grifo nosso)
} 
O artigo continua com demonstrações de apoio ao ministério, embora na Circular Ottoni afirme que desde 14 de julho já discordasse das ideias que predominavam no governo. A negociação de princípios com o grupo que na Circular chama de "monarquistas liberais" é documentada pelo famoso artigo, de 25 de junho de 1831, no qual propõe "lentamente republicanizar a constituição". No artigo transcrito no Independente fala-se apenas na confiança de que entregues a homens respeitáveis e patrióticos como Vasconcelos e Linos o Brasil mostraria que era digno da liberdade. O texto fecha com uma longa exortação ao governo:

mostre o governo energia, e boa fé; cuide em abafar as facções; e cimentar a confiança; seja inexorável na repressão da violência, e da sedição; promova incansavelmente o aumento das rendas públicas; cuide na instrução com grande desvelo, pois ela é o arrimo principal da liberdade; dê proteção ao comércio tratando da abertura de estradas, e da navegação dos rios no interior; numa palavra desempenhe os princípios, que desenvolveu na sua - exposição -, que alcançará a glória de haver salvado a Pátria, de haver bem dirigido a Revolução, e de haver regenerado o Brasil, nas páginas de cuja história verão, se assim obrarem, os atuais ministros, e Regentes, estampados os seus nomes com caracteres indeléveis.

Mesmo que o divórcio entre Ottoni e os moderados não tenha sido total, o fato é que as referências à Sentinela desapareceriam das folhas moderadas. O próprio Ottoni admite que "A Sentinela do Serro cedeu, menos prudentemente, às provocações das gazetas moderadas: foi processada, e viu-se na necessidade de suspender a sua publicação". ${ }^{60}$

Em artigo recente, Wlamir Silva procurou desenvolver sua tese da existência de uma pedagogia moderada que em Minas Gerais teria sufocado todos os germes do liberalismo exaltado. ${ }^{61}$ Para confirmar sua hipótese, submete ao teste a afirmação de alguns historiadores de que Teófilo Ottoni seria um legítimo representante mineiro dessa modalidade de liberalismo. Mesmo questionando a tradicional divisão triádica da vida política nos primeiros anos da regência, ${ }^{62}$ Wlamir a mantém e se vê na necessidade de incluir Ottoni no campo do liberalismo moderado. Muito bem argumentado, utilizando-se para o caso Ottoni das referências presentes na Circular, Wlamir defende que a Sentinela compartilhava um conjunto de referências políticas com os liberais moderados, em especial aqueles elementos da pedagogia que serviu de arma para o combate do radicalismo exaltado.

60 OTTONI, Teófilo Benedito. Circular..., p.24.

61 SILVA, Wlamir. Esmagando a Hydra da discórdia, p.124 e seg.

62 Para uma leitura da composição política e o clima de indefinição política no período da Regência, Cf: BASILE, Marcello. O "negócio mais milindroso": reforma constitucional e composições políticas no Parlamento Regencial (1831-1834). In: NEVES, Lúcia Maria Bastos P. das. (org.) Livros e Impressos: retratos do Setecentos e do Oitocentos. Rio de Janeiro: Eduerj, 2009, p.185-219. 
No entanto, mesmo concordando com o fato, inclusive afirmado pelo próprio Ottoni na Circular, de que ele combateu os anarquistas e radicais, e que não se via como um deles, a segunda parte do argumento parecenos ainda insuficiente. A defesa da moderação não pode ser considerada uma bandeira exclusiva do chamado "liberalismo moderado", bem como não nos parece ser exclusivo desse grupo o uso do discurso civilizatório, a exclusão da plebe ou o republicanismo cívico que ligava cidadania à virtude. Como ignorar que nem Ottoni nem a imprensa mais estreitamente moderada consideravam a Sentinela do Serro um seu igual? Como acreditamos ter sido demonstrado acima, no Aurora a Sentinela foi usada para reforçar o discurso da moderação, mas este uso foi seletivo e não faltaram críticas ao estilo radical do jornal, o que de resto explica a sua perseguição e fechamento em 1832. O momento de maior aproximação dessa imprensa com a Sentinela deu-se nos dias em torno do Sete de abril, desde então podemos verificar uma aproximação mais crítica e mesmo o silenciamento no caso do Universal de Ouro Preto.

A experiência serrana do liberalismo apresenta certas peculiaridades que parecem exigir um tratamento mais cuidadoso. Como destacou recentemente Leonardo Miranda, o grau de mobilização da população no Serro impressiona. Temos notícias pela Sentinela que descreve reuniões com 500 pessoas. Miranda avalia que nesse contingente não estavam apenas os homens bons, mas setores da população que os moderados prefeririam manter excluídos da vida pública. ${ }^{63}$ Descrevendo o clima político na região, Joaquim Felício dos Santos recupera um personagem que talvez nos dê uma ideia da amplitude desse espaço público e da variedade de seus atores:

Em 1828 havia em Tijuco um jovem, Manoel Sabino de Sampaio Lopes. Manoel Sabino, simples ourives, não recebera uma educação acurada, mas possuía imaginação viva, espírito inventivo e sobretudo abundava em entusiasmo pela liberdade: nesse tempo revoltava o despotismo de Pedro I. Nunca saíra da comarca, nunca vira uma tipografia, não possuía a menor ideia dessa portentosa invenção de Guttemberg; só sabia que com a imprensa se fulminavam os déspotas. Liberal exaltado, compreendeu fundar uma tipografia no Tijuco, a fim de publicar um periódico contra o déspota da época, Pedro 1.64

Para concluir, mesmo compreendendo a necessidade de o historiador produzir categorias que estejam para além da consciência dos próprios atores políticos, afinal, Ottoni poderia ser um moderado sem o saber, devemos considerar que ele em mais de uma ocasião se classificou fora do grupo propriamente moderado, preferindo ser visto como um liberal avançado.

63 ARAÚJO MIRANDA, Leonardo Souza de. A democracia da gravata lavada, p.9-10.

64 SANTOS, Joaquim Felício dos. Memórias do districto diamantino da comarca do Sêrro Frio (Província de Minas Gerais). Rio de Janeiro: Tipografia Americana, 1868, p.413. 
Essa caracterização vai ao encontro de conclusões de pesquisas como a de Galdys Sabina, que procura apontar para uma maior diversidade de posições entre os que temos chamado genericamente de liberais exaltados. ${ }^{65}$ Desse modo, acreditamos que a partir dessas diferenças podemos trabalhar para complexificar o esquema triádico e talvez excessivamente normativo que ainda hoje vigora na compreensão desse período.

65 Cf: RIBEIRO, Gladys Sabina. Causa nacional e cidadania: a participação popular e a autonomia na imprensa carioca do início dos anos de 1830. In: NEVES, Lúcia Maria B. P. das; MOREL, Marco; FERREIRA, Tânia Maria Bessone da C. (orgs.) História e Imprensa: representações culturais e práticas de poder. Rio de Janeiro: DP\&A: Faperj, 2006, p.113-41. "Dessa forma, afirmar que os 'exaltados' almejavam a igualdade tendo uma postura antiaristocrática parece exagero. Pergunta-se: de qual grupo de exaltado se fala? Os jornais assim rotulados tinham propostas bem diferentes entre si e não raro criticavam-se uns aos outros". (p.129). Para um esforço de caracterização sintético e bem documentado, talvez mais compatível com os argumentos de Wlamir Silva, ver: BASILE, Marcello. Projetos de Brasil e construção nacional na imprensa fluminense (1831-1835). In: NEVES, Lúcia Maria B. P. das; MOREL, Marco; FERREIRA, Tânia Maria Bessone da C. (orgs.) História e Imprensa, p.60-93. 